\title{
Introduction and Transition
}

\author{
Marvin L. Birnbaum, MD, PhD
}

The beginning, as the proverb says, is half the whole.

Aristotle, Politics. Bk, v. ch.3, sec. 30,

I am retiring as the Editor of Prehospital and Disaster Medicine (PDM), and it is my pleasure to introduce Professor Samuel Stratton, MD, MPH who has assumed the role and responsibilities of the Editor-in-Chief. Sam has served as a Deputy Editor of this Journal for two years during which time we have worked closely together. The transition has been gradual and smooth, and Sam is well-prepared to assume the position as the Editor. He is a Professor in the School of Public Health of the University of California-Los Angeles (UCLA), and is faculty of the UCLA Center for Public Health and Disasters. $\mathrm{He}$ is qualified in Internal and Emergency Medicine and has a Master's Degree in Public Health. He has served as an active member of the Editorial Board for more than a decade and as a member of the Board of Directors of the World Association for Disaster and Emergency Medicine (WADEM) from 2001 through 2009. He chairs the WADEM Research Committee, and has been a co-chair of its Public Health Task Force. Many of you know him from his Editorial Comments published in PDM. He has been integral to the decision to partner with Cambridge University Press as our publisher.
Sam is soft spoken, serious, and is a critical thinker. He possesses excellent writing skills. He is accessible and has demonstrated remarkable leadership skills. Sam is a good friend and I am delighted to have him assume this position. Under his leadership, PDM will continue to be the leading international journal for Disaster and Emergency Medicine.

It has been a great honor to have served as the Editor of PDM for the last 23 years, and to be witness to the gradual maturation of our disciplines. Your support of me, the Editorial Board, and staff has been exceptional. We have come a long way together, but there remains much to accomplish. Sam will lead us along a path of growth and respect that is appropriate for the leading medical journal in its field at a time during which the publishing industry is rapidly changing. Sam will need the same support and encouragement that you have provided for me during my tenure. I wish him and PDM great success.

New times demand new measures and new men;

The world advances, and in time outgrows

The laws that in our fathers' day were best;

And, doubtless, after us, some purer scheme

Will be shaped out by wiser men than we.

JR Lowell, A Glance Bebind the Curtain

doi:10.1017/S1049023X11006583 